UNIVERSIDADE FEDERAL DO RIO GRANDE DO SUL

FACULDADE DE FARMÁCIA

DISCIPLINA DE TRABALHO DE CONCLUSÃO DE CURSO DE FARMÁCIA

MOLECULAR AND BIOCHEMICAL BIOMARKERS FOR DIAGNOSIS AND

THERAPY MONITORIZATION OF NIEMANN-PICK TYPE C PATIENTS

TATIANE GRAZIELI HAMMERSCHMIDT

Porto Alegre, julho de 2017 
UNIVERSIDADE FEDERAL DO RIO GRANDE DO SUL FACULDADE DE FARMÁCIA

DISCIPLINA DE TRABALHO DE CONCLUSÃO DE CURSO DE FARMÁCIA

Trabalho apresentado como requisito parcial para aprovação na Disciplina de

Trabalho de Conclusão do Curso de

Farmácia da Universidade Federal do Rio Grande do Sul

TATIANE GRAZIELI HAMMERSCHMIDT

Orientadora: Prof ${ }^{a} \mathrm{Dr}^{\mathrm{a}}$ Carmen Regla Vargas

Co-Orientadora: $\mathrm{Dr}^{\mathrm{a}}$ Graziela de Oliveira Schmitt Ribas

Porto Alegre, julho de 2017 
Esse artigo foi elaborado segundo as normas da revista International Journal of Developmental Neuroscience (anexo I) na qualidade de "Short Communication". O artigo será submetido para publicação nesta revista após as correções e sugestões da banca revisora. 


\section{MOLECULAR AND BIOCHEMICAL BIOMARKERS FOR DIAGNOSIS AND THERAPY MONITORIZATION OF NIEMANN-PICK TYPE C PATIENTS}

Tatiane Grazieli Hammerschmidta ${ }^{2}$, Graziela de Oliveira Schmitt Ribas ${ }^{\mathrm{d}}$, Carmen Regla Vargas ${ }^{\mathrm{a}, \mathrm{b}, \mathrm{c}, \mathrm{d}}{ }^{*}$

a Departamento de Análises, Faculdade de Farmácia, UFRGS, Avenida Ipiranga, 2752, CEP 90610-000, Porto Alegre, RS, Brazil.

b Programa de Pós-Graduação em Ciências Biológicas, Bioquímica, UFRGS, Rua Ramiro Barcelos, 2600, CEP 90035-003, Porto Alegre, RS, Brazil.

c Programa de Pós-Graduação em Ciências Farmacêuticas, UFRGS, Av. Ipiranga, 2752, CEP 90610-000, Porto Alegre, RS, Brazil.

d Serviço de Genética Médica, HCPA, Rua Ramiro Barcelos, 2350, CEP 90035 003, Porto Alegre, RS, Brazil.

* Corresponding author: Serviço de Genética Médica, HCPA, Rua Ramiro Barcelos, 2350, CEP 90035-003, Porto Alegre, RS, Brazil.

Telephone: +555133598011

Telefax: +55 5133598010

E-mail address: crvargas@hcpa.ufrgs.br (Carmen R. Vargas) 


\section{Abstract}

Niemann-Pick type C (NP-C), one of 50 inherited lysosomal storage disorders caused by NPC protein impairment that leads to unesterified cholesterol accumulation in late endosomal/lysosomal compartments. The clinical manifestations of NP-C includes hepatosplenomegaly, neurological and psychiatric symptoms. Current diagnosis for NP-C is based on observation of the accumulated cholesterol in fibroblasts of affected individuals, using an invasive and time expensive test, called Filipin staining. Lately, two metabolites that are markedly increased in NP-C patients are arising as biomarkers for this disease

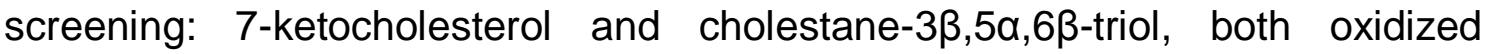

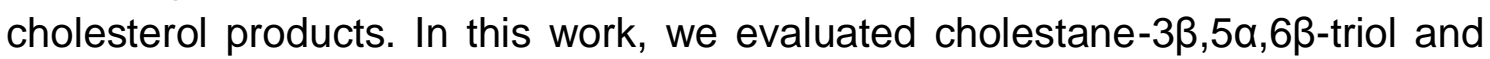
chitotriosidase levels, Filipin staining and molecular analysis for NPC mutation in 76 individuals with NP-C suspicion. Also, we analyzed cholestane- $3 \beta, 5 \alpha, 6 \beta$-triol levels in 7 patients with previous NP-C diagnosis under treatment with miglustat, in order to verify its value as a tool for therapy monitoring. For cholestane$3 \beta, 5 \alpha, 6 \beta$-triol analysis using molecular assay as golden standard we found $88 \%$ of sensibility, $96.08 \%$ of specificity, a positive and negative predictive value calculated in $91.67 \%$ and $94.23 \%$, respectively. Chitotriosidase levels were increased in patients with positive molecular analysis for NP-C. For Filipin staining, it was found 1 false positive, 7 false negative and 24 inconclusive cases, showing that this assay has important limitations in NP-C diagnosis. Besides, we found a significant decrease in cholestane- $3 \beta, 5 \alpha, 6 \beta$-triol concentrations in NP-C patients under therapy with miglustat when compared to non-treated patients. These data show that cholestane-3 $\beta, 5 \alpha, 6 \beta$-triol analysis has a high potential to be an important NP-C screening assay, and also can be used for therapy monitorization with miglustat in NP-C patients.

\section{Keywords}

Niemann-Pick type C, oxysterols, Filipin staining, screening, sensibility, specificity, miglustat, therapy monitorization.

\section{Abbreviations}

NP-C, Niemann-Pick type C; LSD, lysosomal storage disorder; CNS, central nervous system; 7-KC, 7-ketocholesterol; GC/MS, gas chromatography/mass spectrometry; LC/MS-MS, liquid chromatography/tandem mass spectrometry; LDL, low density lipoprotein; LE, late endosomal; ROS, reactive oxygen species; CSF, cerebrospinal fluid; HSEM, horizontal saccadic eye movement . 


\section{Molecular and biochemical biomarkers for diagnosis and therapy monitorization of Niemann-Pick type $C$ patients}

\section{Introduction}

Niemann-Pick type C (NP-C) is a lysosomal lipid storage disease (LSD) with autosomal recessive inheritance, caused by mutations in NPC1 or NPC2 genes and mainly characterized by unesterified cholesterol accumulation in late endosomal/lysosomal (LE/L) compartments [1]. In result of this genetic defect, there is an accumulation of other lipids, such as glucosylceramide, GM1 and GM2 gangliosides in peripheral tissues (liver, spleen and lungs) and in central nervous system (CNS) of the affected individuals [2]. In this way, clinical presentation is extremely heterogenous and includes hepatosplenomegaly, neonatal jaundice, dysarthria, dysphagia, vertical supranuclear gaze palsy, psychiatric and/or cognitive dysfunction and it may vary between patients in terms of age-onset and disease severity, delaying the recognition of the disease [2]. Regarding its rarity, NP-C incidence is estimated in $1 / 89,000$, but this data may be significant underascertainment of a late-onset NPC1 phenotype [3].

Despite there is no cure for NP-C, the management of symptoms is an important goal in therapy for these patients [4]. Miglustat, a small iminosugar molecule able to cross the blood-brain barrier and to reversibly inhibit glucosylceramide synthase (the first enzyme in glycosphingolipid synthesis) was proposed for the treatment of the disease [5]. The efficacy of miglustat on neurological manifestations progression has been studied in NPC patients enrolled in international clinical trials and observational studies. Data from oneyear treatment of juvenile and adult NPC patients suggested that miglustat improves or stabilizes several neurological manifestations [5,6]. Cyclodextrins are also showing some promising results in several studies, but the mechanisms are not yet completely established $[7,8]$.

Due to its heterogeneity in symptoms and clinical nature, prompt diagnosis for NP-C is a challenge. Once considered standard gold assay for NP-C diagnosis, Filipin staining is based in a coloration using a fluorescent antibiotic, which binds to cholesterol accumulated in fibroblasts from NP-C patients. However, a variant profile in fluorescent pattern can cause doubts in assay interpretation. Besides, Filipin test is an invasive and expensive procedure, requiring a specialized center to perform it [9]. Determination of chitotriosidase is also used as a general and potential indicator of LSD, including NP-A, NP-B and NP-C. However, normal levels of this enzyme may occur in these patients, showing a lack of sensibility and specificity of this assay [9]. Therefore, definitive diagnosis depends on molecular analysis of NPC1 and NPC2 genes for most cases.

In NPC deficient cells, there is an association between oxidative stress and accumulated cholesterol by increased production of reactive oxygen species 
and oxidative damage [10]. Cholesterol can suffer oxidation in different ways, and it could be mediated by enzymes or in non-enzymatic reactions (Figure 1). Oxidized cholesterol products, specifically cholestane- $3 \beta, 5 \alpha, 6 \beta$-triol $(3 \beta, 5 \alpha, 6 \beta-$ triol) and 7-ketocholesterol (7-KC), are markedly increased in plasma of NP-C patients and in animal models, whereas remain normal in other LSD [11]. These findings indicate that $3 \beta, 5 \alpha, 6 \beta$-triol and $7-\mathrm{KC}$ are NPC1 disease-specific biochemical markers and suggest a possible utility of these markers in diagnosis and therapeutic evaluation of NPC1 disease [11]. Determination of these metabolites can be performed using gas chromatography/mass spectrometry (CG/MS) or by liquid chromatography/tandem mass spectrometry (LC-MS/MS) methods [12,13]. Therefore, oxysterols analysis by LC-MS/MS became an alternative and non-invasive assay to screen potential NP-C patients, as well as a tool for treatment monitoring. However its correlation with tests currently used for NP-C diagnosis must be better investigated.

In order to evaluate the $3 \beta, 5 \alpha, 6 \beta$-triol measurement for NP-C therapy monitorization and also as a biomarker for NP-C diagnosis, in this work we analyzed $3 \beta, 5 \alpha, 6 \beta$-triol and chitotriosidase levels, Filipin staining and mutations in NPC genes in biological samples from patients with NP-C suspicious and in treated NP-C patients referred to our specialized center in South Brazil.

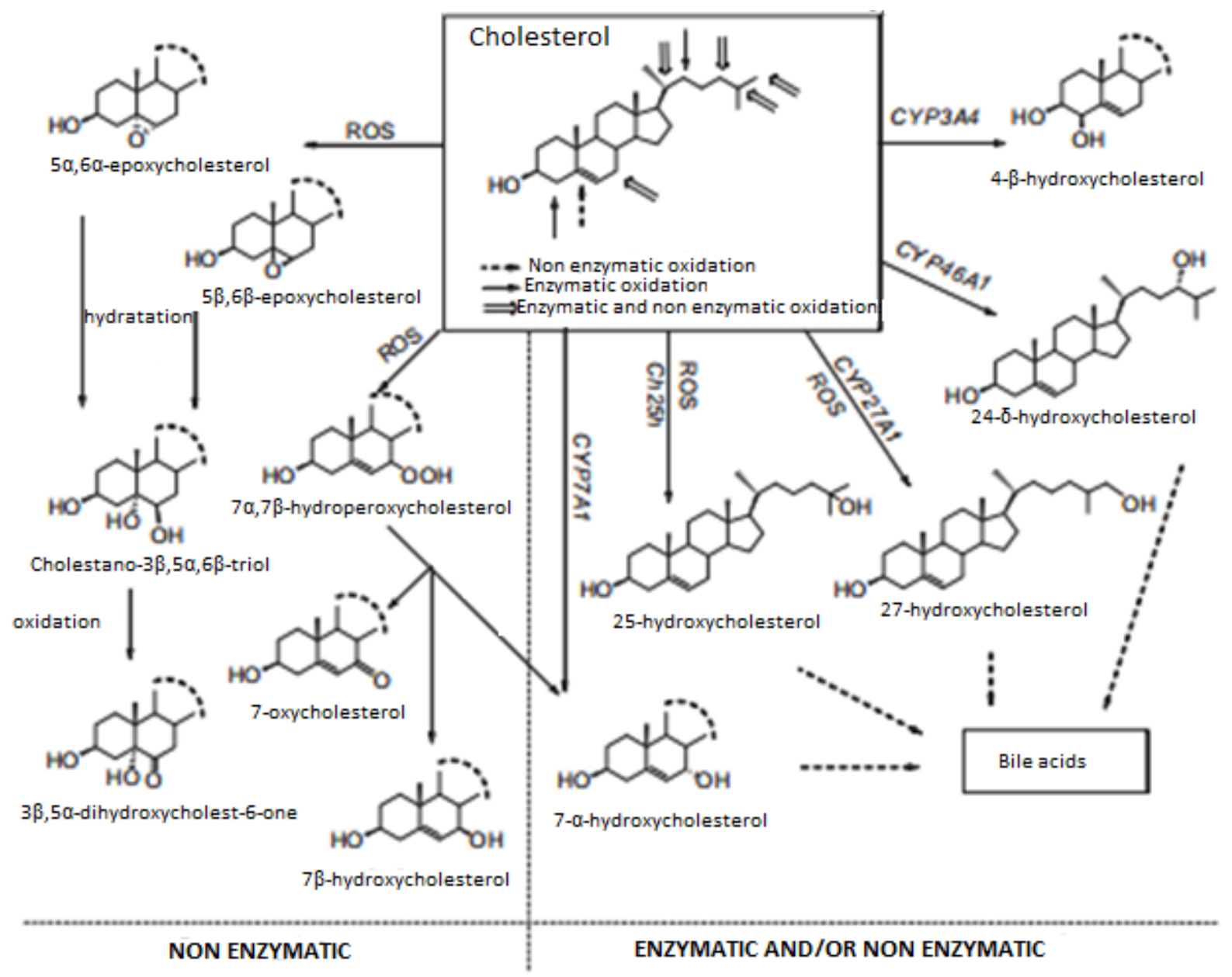

Fig. 1: Different pathways of cholesterol oxidation 


\section{Materials and methods}

\subsection{Samples}

Skin biopsy and blood samples were obtained from 76 individuals with suspicious of NP-C disease in Medical Genetics Service of Hospital de Clínicas de Porto Alegre, Brazil. Additionally, 7 blood samples from patients with previous diagnosis of NP-C under miglustat therapy (therapeutic regime: $200 \mathrm{mg}$ thrice a day) were collected. These blood samples were collected in tubes with EDTA as anticoagulant, centrifuged for five minutes at $3000 \mathrm{rpm}$ and plasma was frozen at $-80 \stackrel{\circ}{\circ}$. The clinical features presented by these patients include dystonia, dysphagia, seizures, vertical supranuclear palsy and psychiatric disorders.

This work was carried out according to the Code of Ethics of the World Medical Association (Declaration of Helsinki). All subjects in this study signed an informed consent, and it was approved by the Ethics Committee of Hospital de Clínicas de Porto Alegre (HCPA), RS, Brazil under the registration number 13-0239.

\subsection{Cholestane- $3 \beta, 5 \alpha, 6 \beta$-triol analysis}

Levels of triol were determined by LC-MS/MS in EDTA-plasma, using cholestane- $3 \beta, 5 \alpha, 6 \beta$-triol D7 as internal standard and derivatization with dimetylglycine esters, according to Jiang et al [11], with some modifications. The chromatographic separation was performed on a column ACE $3 \mathrm{C} 18(4.6 \times 150 \mathrm{~mm}, 3 \mu \mathrm{m})$ using a gradient of mobile phase A $(0.1 \%$ formic acid $+1 \mathrm{mM}$ ammonium acetate in water) and mobile phase $\mathrm{B}(0.1 \%$ formic acid $+1 \mathrm{mM}$ ammonium acetate in methanol). Detection was performed with a Waters Quattro Micro API tandem mass spectrometer in positive atmospheric-pressure chemical ionization (APCl) and multiple reaction monitoring (MRM) mode. The optimized MS/MS conditions were as follows. $\mathrm{APCl}$ probe temperature and source temperature were $500^{\circ} \mathrm{C}$ and $120^{\circ} \mathrm{C}$, respectively; cone voltage and coll energy were $30 \mathrm{~V}$ and $20 \mathrm{eV}$, respectively; desolvation gas flow and cone gas flow were $600 \mathrm{~L} / \mathrm{h}$ and $50 \mathrm{~L} / \mathrm{h}$, respectively; monitored mass transitions were $591.5 \rightarrow 104$ for the triol and $598.8 \rightarrow 103.8$ for the internal standard; retention time was $5.5 \mathrm{~min}$. and quantification was based on standard curve ranging from 2 to $400 \mathrm{ng} / \mathrm{mL}$ for the triol [14].

\subsection{Chitotriosidase assay}

Plasma enzyme determination was performed according to Hollak et al [15], using 4-methylumbellifery| $\beta$-DN, $\mathrm{N}^{\prime}, \mathrm{N}^{\prime \prime}$-triacetylchitotrioside as reaction substrate. The mixture for the enzyme assay was composed by 5 
$\mu \mathrm{L}$ of acidified plasma and $26 \mu \mathrm{M}$ of substrate dissolved in $100 \mathrm{mM}$ citrate plus $200 \mathrm{mM}$ phosphate buffer ( $\mathrm{pH}$ 5.2), obtained a total volume of 105 $\mu \mathrm{L}$. This mixture was incubated for $15^{\prime}$ at $37^{\circ} \mathrm{C}$. Glycine-sodium hydroxide buffer $(0.5 \mathrm{M}, \mathrm{pH} 10.3)$ was used as stop solution for the reaction and the fluorescence was determined with a Hitachi F2000 spectrofluorometer $(\lambda$ excitation $365 \mathrm{~nm}$ and emission $450 \mathrm{~nm}$ ). Normal range was considered between 8.8 and $132.0 \mathrm{nmol} / \mathrm{h} / \mathrm{mL}$.

\subsection{Filipin staining}

Skin biopsy samples were used for fibroblasts culture with HAM-F10 medium and $10 \%$ of Fetal Calf Serum. After the cells reached confluence, Low Density Lipoprotein (LDL) was added to the culture. After two days, cells were transferred to slides and stained with Filipin reagent for histological examination in a fluorescent microscope. Intracellular lipid accumulation was determined as described in Blanchette-Mackie et al [16]; 'classical' pattern of cholesterol accumulation showed a strong fluorescence in perinuclear vesicles (positive). The pattern of cells samples was categorized in normal (clear, no fluorescence), inconclusive or variant (moderated fluorescence) or typical or "classical" (high fluorescence).

\subsection{Molecular analysis}

Mutation analysis was performed using DNA isolated by standard method from patients' blood samples. Coding sequences and flanking regions of the NPC1 and the NPC2 genes were amplified with PCR, purified and submitted to direct DNA sequencing using the BigDye1 Terminator Cycle Sequencing kit v. 3.1 (Applied Biosystems, Foster City, CA, USA), following the manufacturer's instructions. Products were then submitted to capillary electrophoresis in an ABI PRISM1 3130xI Genetic Analyzer, and sequences were analyzed with DNA Sequencing Analysis software v. 5.2 (Applied Biosystems). Mutations were confirmed by sequencing an independent DNA sample with both forward and reverse primers. Molecular analyses were conducted in blood of all patients of this study.

\subsection{Statistical analysis}

All results were expressed as mean \pm standard deviation (SD). Unpaired Student's t test was used for groups comparison, and difference was considered significant when $p<0.05$. All analysis and graphs were performed using the software GraphPad Prism ${ }^{\circledR}$ (GraphPad Software Inc., San Diego, CA, USA - version 7.0 for Windows ${ }^{\circledR}$ ) in a compatible PC. 


\section{Results}

Subjects were segregated in 2 different groups: patients with $3 \beta, 5 \alpha, 6 \beta$-triol levels higher than $100 \mathrm{ng} / \mathrm{mL}$ (group A) and lower than $100 \mathrm{ng} / \mathrm{mL}$ (group B). This separation was established according to the cut-off value founded for this analyte in our laboratory. Table 1 shows that individuals from group A also presented higher chitotriosidase activity compared to group $\mathrm{B}$, although this biomarker is not specific for NP-C, and also can be found increased in others LSD, such as Gaucher disease and NP-A/B [17]. Molecular analysis showed that 2 patients from group A did not have any mutation in NPC gene, excluding the existence of the disease. In other hand, 3 individuals from group $B$ presented positive molecular analysis for NPC, despite low levels of $3 \beta, 5 \alpha, 6 \beta$-triol. Results of molecular analysis are summarized in table 2. Considering these data and applying MedCalc software, the analysis of $3 \beta, 5 \alpha, 6 \beta$-triol levels has $88 \%$ of sensibility, $96.08 \%$ of specificity, a positive and negative predictive value calculated in $91.67 \%$ and $94.23 \%$, respectively. For these calculations, it was used molecular analysis as gold standard. Filipin staining was not performed in all individuals since $3 \beta, 5 \alpha, 6 \beta$-triol analysis was previously established as a good screening assay for NP-C [14].

The therapy with miglustat and its effect in $3 \beta, 5 \alpha, 6 \beta$-triol levels was also evaluated. It can be observed in table 3 and figure 2 that $3 \beta, 5 \alpha, 6 \beta$-triol levels are significantly lower in treated patients when compared to non-treated individuals, showing that this metabolite could be used not only for screening but also for therapy monitorization in NP-C.

Table 1: Results of Filipin staining, chitotriosidase activity and molecular analysis in patients with cholestane-3 $3,5 \alpha, 6 \beta-$ triol levels higher than $100 \mathrm{ng} / \mathrm{mL}$ (Group A) and lower than $100 \mathrm{ng} / \mathrm{mL}$ (Group B).

\begin{tabular}{|c|c|c|c|c|c|c|}
\hline $\begin{array}{l}3 \beta, 5 \alpha, 6 \beta- \\
\text { triol } \\
\text { concentrati } \\
\text { on }(\mathrm{ng} / \mathrm{mL} \text {; }\end{array}$ & $\begin{array}{l}{ }^{1} \mathrm{CT} \text { activity } \\
\text { (nmol/h/mL; } \\
\text { mean } \\
\pm S D)\end{array}$ & $\begin{array}{l}\text { Positive } \\
\text { cases by } \\
\text { Filipin } \\
\text { staining }\end{array}$ & $\begin{array}{l}\text { Negative } \\
\text { cases by } \\
\text { Filipin } \\
\text { staining }\end{array}$ & $\begin{array}{l}\text { Inconclusi } \\
\text { ve cases } \\
\text { by Filipin } \\
\text { staining }\end{array}$ & $\begin{array}{l}\text { Positive } \\
\text { cases by } \\
\text { molecular } \\
\text { analysis }\end{array}$ & $\begin{array}{l}\text { Negative } \\
\text { cases by } \\
\text { molecular } \\
\text { analysis }\end{array}$ \\
\hline
\end{tabular}

\begin{tabular}{llllllll}
\hline $\begin{array}{l}\text { Group A } \\
(\mathbf{n = 2 4 )}\end{array}$ & $164.6 \pm 10.67$ & $929.3 \pm 346.5$ & 10 & 0 & 2 & 22 & 2 \\
\hline $\begin{array}{l}\text { Group B } \\
(\mathbf{n = 5 2})\end{array}$ & $34.7 \pm 3.803$ & $174.5 \pm 49.73$ & 1 & 7 & 24 & 3 & 49 \\
\hline
\end{tabular}

1 : Chitotriosidase 
Table 2: Results for molecular analysis

\begin{tabular}{l|l}
\multicolumn{1}{c|}{ Molecular analysis } & \multicolumn{1}{c}{ Patients } \\
\hline Heterozygous for mutations p.D945N and p.F1221SfsX20 & 1 \\
\hline Homozygous for mutation p.A1035 V & 5 \\
\hline Heterozygous for mutations p.I923V and p.A1035 V & 1 \\
\hline Heterozygous for mutations p.N195Kfsp ${ }^{\star}$ and p.F1221SfsX*20 & 1 \\
\hline Heterozygous for mutations c.114-122del19 and p.F1221SfsX20 & 2 \\
\hline Homozygous for mutation p.V694M & 2 \\
\hline Homozygous for mutation p.F1221SfsX20 & 2 \\
\hline Heterozygous for mutations p.R1186H and p.F1221SfsX20 & 1 \\
\hline Heterozygous for sequence variation p.G992R and heterozygous for & 1 \\
mutation p.G1140V. & \\
\hline Heterozygous for mutations p.A1035V and p.E1166K & 1 \\
\hline Heterozygous for mutations p.S151Ffs ${ }^{*} 70$ and p.F1221SfsX20 & 1 \\
\hline Heterozygous for variations p.G910S and p.G992W & 1 \\
\hline Homozygous for mutation p.Q710Rfs ${ }^{\star 27}$ & 1 \\
\hline Homozygous for mutation p.P1007V & 1 \\
\hline Homozygous for mutation p.P1007A. & 1 \\
\hline Homozygous for mutation p.R518M & 1 \\
\hline Heterozygous for variation p.G992R and heterozygous for mutations & 1 \\
p.A1035V. & 1 \\
\hline Heterozygous for mutations p.P1007A V and p.E1166K & \\
\hline
\end{tabular}

Table 3: Cholestane-3 $\beta, 5 \alpha, 6 \beta$-triol concentration, age of NP-C patients and therapy duration

\begin{tabular}{|c|c|c|c|}
\hline & $\begin{array}{l}3 \beta, 5 \alpha, 6 \beta \text {-triol } \\
\text { concentration }(\mathrm{ng} / \mathrm{mL} \text {; } \\
\text { mean } \pm S D)\end{array}$ & $\begin{array}{l}\text { Age (years; } \\
\text { mean士SD) }\end{array}$ & $\begin{array}{l}\text { Treatment duration } \\
\text { (years; mean士SD) }\end{array}$ \\
\hline Treated $(\mathrm{n}=7)$ & $44.47 \pm 13.3$ & $23.44 \pm 11.95$ & $4.29 \pm 1.80$ \\
\hline Non-treated $(n=26)$ & $148.5 \pm 10.0$ & $12.5 \pm 13.63$ & - \\
\hline
\end{tabular}

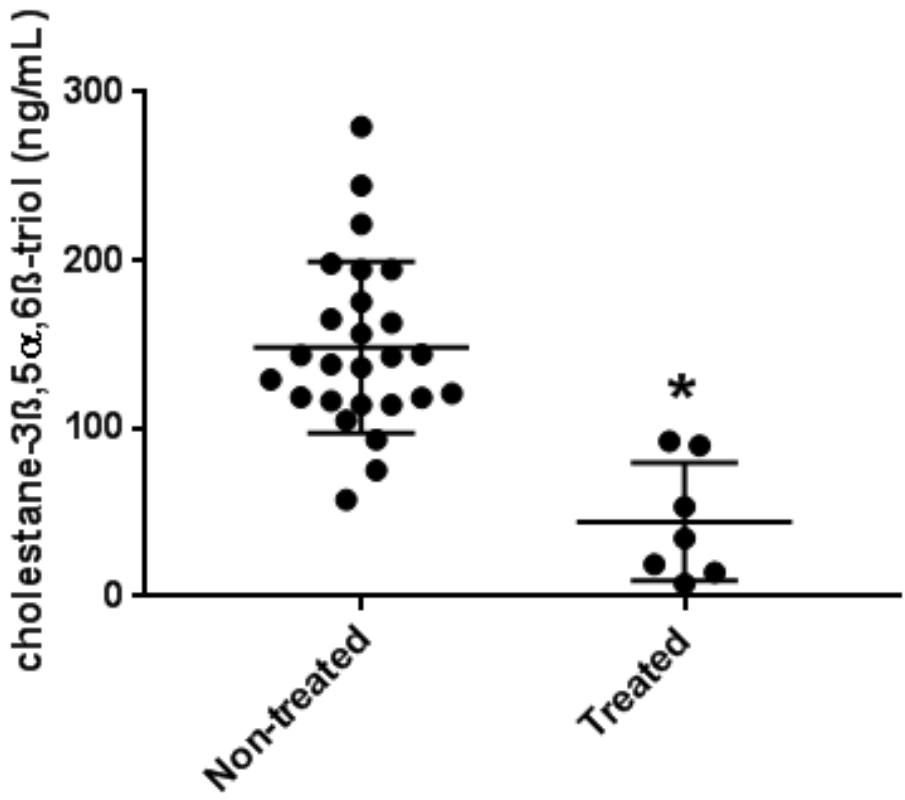

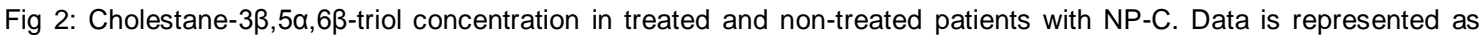
mean $\pm S D$. Student's $t$ test was performed, and ${ }^{*} p<0.0001$ when compared with non-treated individuals. 


\section{Discussion}

NP-C is a LSD currently conceived as a lipid trafficking disorder. Impaired egress of cholesterol from the late endosomal/lysosomal compartments is a specific key element of the pathogenesis [17]. Accumulated cholesterol in viscera and CNS can be oxidized by reactive oxygen species (ROS) in a nonenzymatic reaction forming oxysterols, mainly $3 \beta, 5 \alpha, 6 \beta$-triol and $7-\mathrm{KC}$, which can be measured in plasma and used as biomarkers for diagnosis and therapy monitorization of NP-C [11]. In this work, we determined $3 \beta, 5 \alpha, 6 \beta$-triol levels, chitotriosidase activity, Filipin staining and NPC gene mutations from 76 individuals with NP-C suspicion, in order to investigate the potential of $3 \beta, 5 \alpha, 6 \beta-$ triol analysis for NP-C screening. The current method used for diagnosis in NP$C$ is Filipin staining, although this analysis shows a difficult interpretation and a variant presentation that can confuse the analyst [18]. For Filipin analysis, it was found 1 false positive, 7 false negative and 24 inconclusive cases, showing the limitations of this assay. The sensibility (88\%) and specificity $(96.08 \%)$ of $3 \beta, 5 \alpha, 6 \beta$-triol analysis verified by this work is consistent with previous studies $[11,14,19]$, and reaffirm the high potential of this metabolite for screening and its importance in NP-C diagnosis, especially when Filipin cannot be performed or it is inconclusive. Even so, considering that the predictive positive value of $3 \beta, 5 \alpha, 6 \beta$-triol was $91 \%$, these data reinforce the crucial role of molecular analysis for definitive diagnosis, that should be performed in all individuals with a strong clinical suspicion, independent of $3 \beta, 5 \alpha, 6 \beta$-triol concentrations.

Progressive neurological manifestations in NP-C have a profound effect on life's quality of patients and their families. The correct and early identification of NP-C along with the appropriate use of symptomatic and disease-specific therapies can dramatically improve life's quality for all those affected. Currently therapy for NP-C patients consists in a symptomatic treatment altogether with the use of miglustat to reduce neurological impairment. Miglustat is a small molecule that can cross the blood-brain barrier and acts as an inhibitor for the glucosylceramide synthase enzyme, decreasing glycosphingolipids, GM2 and GM3 levels in NP-C patients [20]. Besides, miglustat improves the traffic lipids in lymphocytes type B of NP-C patients [21], and also decrease lipid peroxidation and increase antioxidant status in NP-C1 patients [10]. In this context, our study found a significant $3 \beta, 5 \alpha, 6 \beta$-triol decrease levels in patients treated with miglustat when compared to non-treated patients, probably caused by reduced cholesterol availability for oxidation [22] and also providing a less oxidative environment at a cellular level of these patients. Currently monitorization of miglustat efficacy in NP-C patients consists in clinical evaluation of neurologic symptoms (e.g. ambulation, manipulation, language and swallowing) as well as horizontal saccadic eye movement velocity (HSEM) [20]. In this way, our data shows that miglustat provides an improvement in biochemical status in treated individuals reducing $3 \beta, 5 \alpha, 6 \beta$-triol levels and this metabolite can be successfully used as a therapy monitorization for NP-C. 
Porter et al found an increase of $3 \beta, 5 \alpha, 6 \beta$-triol levels in mice brain tissue and in NP-C patients cerebrospinal fluid (CSF) [13], showing a possible role of this metabolite in neurological manifestations of these individuals. As we found a decrease in $3 \beta, 5 \alpha, 6 \beta$-triol plasma levels in patients treated with miglustat, and once this therapy can slow down, or even decrease neurodegeneration, we can hypothesize that $3 \beta, 5 \alpha, 6 \beta$-triol reduction could be associated with this improvement. However, further studies are necessary to explain how this mechanism works in NP-C disease.

\section{Conclusion}

Taken together, our presented data shows that the cholestane-3 $3,5 \alpha, 6 \beta-$ triol analysis by LC-MS/MS can be used for Niemann-Pick type $C$ disease diagnosis and screening with good sensibility and specificity. This biomarker emerges as a potential candidate to substitute the current test for NP-C: the Filipin staining. In the other hand, the $3 \beta, 5 \alpha, 6 \beta$-triol analysis also can be used for therapy monitoring, since a significant decrease in this metabolite levels was observed in patients treated with miglustat when compared to non-treated patients. Although the mechanism of this effect is not completely clear, it may be related to improve in lipid traffic and decrease in oxidative stress caused by this treatment.

\section{Aknowledgements}

The authors are grateful to the partners of the NPC Brazil Network, including physicians, technicians, families and patients.

\section{Declaration of interest}

The authors declare that there is no conflict of interests.

\section{Funding informations}

This work was supported in part by grants from Brazilian foundation Comissão de Aperfeiçoamento de Pessoal de Ensino Superior (CAPES), Comissão Nacional de Desenvolvimento Científico e Tecnológico (CNPq), Fundação de Amparo à Pesquisa no Rio Grande do Sul (FAPERGS) and Fundo de Amparo à Pesquisa e Eventos (FIPE/ HCPA-Brazil 13-0239). The NPC Brazil Network is partially funded by an unrestricted grant from Actelion (05168). 


\section{References}

1. Vanier MT, Millat G: Niemann-Pick disease type C. Clin Genet 2003 Oct;64:269-281.

2. Patterson MC: A riddle wrapped in a mystery: understanding Niemann-Pick disease, type C. Neurologist 2003 Nov;9:301-310.

3. Wassif CA, Cross JL, Iben J, Sanchez-Pulido L, Cougnoux A, Platt FM, et al.: High incidence of unrecognized visceral/neurological late-onset Niemann-Pick disease, type $\mathrm{C} 1$, predicted by analysis of massively parallel sequencing data sets. Genet Med 2016 Jan;18:41-48.

4. Patterson MC, Hendriksz CJ, Walterfang M, Sedel F, Vanier MT, Wijburg F, et al.: Recommendations for the diagnosis and management of NiemannPick disease type C: an update. Mol Genet Metab 2012 Jul;106:330-344.

5. Fecarotta S, Romano A, Della Casa R, Del Giudice E, Bruschini D, Mansi $G$, et al.: Long term follow-up to evaluate the efficacy of miglustat treatment in Italian patients with Niemann-Pick disease type C. Orphanet J Rare Dis 2015 Feb 27;10:22.

6. Patterson MC, Vecchio D, Prady H, Abel L, Wraith JE: Miglustat for treatment of Niemann-Pick $C$ disease: a randomised controlled study. Lancet Neurol 2007 Sep;6:765-772.

7. Atger VM, de la Llera Moya M, Stoudt GW, Rodrigueza WV, Phillips MC, Rothblat GH: Cyclodextrins as catalysts for the removal of cholesterol from macrophage foam cells. J Clin Invest 1997 Feb 15;99:773-780.

8. Aqul A, Liu B, Ramirez CM, Pieper AA, Estill SJ, Burns DK, et al.: Unesterified cholesterol accumulation in late endosomes/lysosomes causes neurodegeneration and is prevented by driving cholesterol export from this compartment. J Neurosci 2011 Jun 22;31:9404-9413.

9. Vanier MT, Gissen P, Bauer P, Coll MJ, Burlina A, Hendriksz CJ, et al.: Diagnostic tests for Niemann-Pick disease type C (NP-C): A critical review. Mol Genet Metab 2016 Aug;118:244-254.

10. Ribas GS, Pires R, Coelho JC, Rodrigues D, Mescka CP, Vanzin CS, et al.: Oxidative stress in Niemann-Pick type C patients: a protective role of $\mathrm{N}$ butyl-deoxynojirimycin therapy. Int J Dev Neurosci 2012 Oct;30:439-444.

11. Jiang X, Sidhu R, Porter FD, Yanjanin NM, Speak AO, te Vruchte DT, et al.: A sensitive and specific LC-MS/MS method for rapid diagnosis of NiemannPick C1 disease from human plasma. J Lipid Res 2011 Jul;52:1435-1445.

12. Boenzi S, Deodato F, Taurisano R, Goffredo BM, Rizzo C, Dionisi-Vici C:

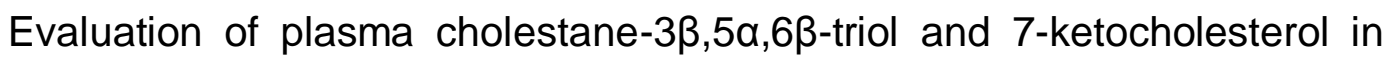
inherited disorders related to cholesterol metabolism. J Lipid Res 2016 Mar;57:361-367. 
13. Porter FD, Scherrer DE, Lanier MH, Langmade SJ, Molugu V, Gale SE, et al.: Cholesterol oxidation products are sensitive and specific blood-based biomarkers for Niemann-Pick C1 disease. Sci Transl Med 2010 Nov 3;2:5681.

14. Ribas GS, Souza HM, de Mari J, Deon M, Mescka C, Saraiva-Pereira ML, et al.: Selective screening of Niemann-Pick type $C$ Brazilian patients by cholestane-3 $\beta, 5 \alpha, 6 \beta$-triol and chitotriosidase measurements followed by Filipin staining and NPC1/NPC2 gene analysis. Clin Chim Acta 2016 Aug 1;459:57-62.

15. Hollak CE, van Weely S, van Oers MH, Aerts JM: Marked elevation of plasma chitotriosidase activity. A novel hallmark of Gaucher disease. J Clin Invest 1994 Mar;93:1288-1292.

16. Blanchette-Mackie EJ, Dwyer NK, Amende LM, Kruth HS, Butler JD, Sokol $\mathrm{J}$, et al.: Type-C Niemann-Pick disease: low density lipoprotein uptake is associated with premature cholesterol accumulation in the Golgi complex and excessive cholesterol storage in lysosomes. Proc Natl Acad Sci U S A 1988 Nov;85:8022-8026.

17. Sheth JJ, Sheth FJ, Oza NJ, Gambhir PS, Dave UP, Shah RC: Plasma chitotriosidase activity in children with lysosomal storage disorders. Indian J Pediatr 2010 Feb;77:203-205.

18. Vanier MT: Complex lipid trafficking in Niemann-Pick disease type C. J Inherit Metab Dis 2015 Jan;38:187-199.

19. Vanier MT, Latour P: Laboratory diagnosis of Niemann-Pick disease type C: the Filipin staining test. Methods Cell Biol 2015 Jan 14;126:357-375.

20. Reunert J, Fobker M, Kannenberg F, Du Chesne I, Plate M, Wellhausen J, et al.: Rapid Diagnosis of 83 Patients with Niemann Pick Type C Disease and Related Cholesterol Transport Disorders by Cholestantriol Screening. EBioMedicine 2016 Feb;4:170-175.

21. Lyseng-Williamson KA: Miglustat: a review of its use in Niemann-Pick disease type C. Drugs 2014 Jan;74:61-74.

22. Lachmann RH, te Vruchte D, Lloyd-Evans E, Reinkensmeier G, Sillence DJ, Fernandez-Guillen $\mathrm{L}$, et al.: Treatment with miglustat reverses the lipidtrafficking defect in Niemann-Pick disease type C. Neurobiol Dis 2004 Aug;16:654-658. 


\section{ANEXO I - NORMAS PARA PUBLICAÇÃO NA REVISTA INTERNATIONAL JOURNAL OF DEVELOPMENTAL NEUROSCIENCE}

\section{GUIDE FOR AUTHORS}

NEW SUBMISSIONS

Submission to this journal proceeds totally online and you will be guided stepwise through the creation and uploading of your files. The system automatically converts your files to a single PDF file, which is used in the peer-review process. As part of the Your Paper Your Way service, you may choose to submit your manuscript as a single file to be used in the refereeing process. This can be a PDF file or a Word document, in any format or layout that can be used by referees to evaluate your manuscript. It should contain high enough quality figures for refereeing. If you prefer to do so, you may still provide all or some of the source files at the initial submission. Please note that individual figure files larger than 10 MB must be uploaded separately.

\section{References}

There are no strict requirements on reference formatting at submission. References can be in any style or format as long as the style is consistent. Where applicable, author(s) name(s), journal title/book title, chapter title/article title, year of publication, volume number/book chapter and the pagination must be present. Use of DOI is highly encouraged. The reference style used by the journal will be applied to the accepted article by Elsevier at the proof stage. Note that missing data will be highlighted at proof stage for the author to correct.

\section{Formatting requirements}

There are no strict formatting requirements but all manuscripts must contain the essential elements needed to convey your manuscript, for example Abstract, Keywords, Introduction, Materials and Methods, Results, Conclusions, Artwork and Tables with Captions. If your article includes any Videos and/or other Supplementary material, this should be included in your initial submission for peer review purposes. Divide the article into clearly defined sections.

\section{Figures and tables embedded in text}

Please ensure the figures and the tables included in the single file are placed next to the relevant text in the manuscript, rather than at the bottom or the top of the file. The corresponding caption should be placed directly below the figure or table.

\section{Article structure}

\section{Subdivision - numbered sections}

Divide your article into clearly defined and numbered sections. Subsections should be numbered 1.1 (then 1.1.1, 1.1.2,), 1.2, etc. (the abstract is not included in section numbering). Use this numbering also for internal cross-referencing: do 
not just refer to 'the text'. Any subsection may be given a brief heading. Each heading should appear on its own separate line.

\section{Introduction}

State the objectives of the work and provide an adequate background, avoiding a detailed literature survey or a summary of the results.

\section{Material and methods}

Provide sufficient detail to allow the work to be reproduced. Methods already published should be indicated by a reference: only relevant modifications should be described.

\section{Theory/calculation}

A Theory section should extend, not repeat, the background to the article already dealt with in the Introduction and lay the foundation for further work. In contrast, a Calculation section represents a practical development from a theoretical basis.

\section{Results}

Results should be clear and concise.

\section{Discussion}

This should explore the significance of the results of the work, not repeat them. A combined Results and Discussion section is often appropriate. Avoid extensive citations and discussion of published literature.

\section{Conclusions}

The main conclusions of the study may be presented in a short Conclusions section, which may stand alone or form a subsection of a Discussion or Results and Discussion section.

\section{Appendices}

If there is more than one appendix, they should be identified as $A, B$, etc. Formulae and equations in appendices should be given separate numbering: Eq. (A.1), Eq. (A.2), etc.; in a subsequent appendix, Eq. (B.1) and so on. Similarly for tables and figures: Table A.1; Fig. A.1, etc.

\section{Essential title page information}

- Title: Concise and informative. Titles are often used in information-retrieval systems. Avoid abbreviations and formulae where possible.

- Author names and affiliations: Please clearly indicate the given name(s) and family name(s) of each author and check that all names are accurately spelled. Present the authors' affiliation addresses (where the actual work was done) below the names. Indicate all affiliations with a lowercase superscript letter immediately after the author's name and in front of the appropriate address. Provide the full postal address of each affiliation, including the country name and, if available, the e-mail address of each 
author.

- Corresponding author: Clearly indicate who will handle correspondence at all stages of refereeing and publication, also post-publication. Ensure that the email address is given and that contact details are kept up to date by the corresponding author.

- Present/permanent address: If an author has moved since the work described in the article was done, or was visiting at the time, a 'Present address' (or 'Permanent address') may be indicated as a footnote to that author's name. The address at which the author actually did the work must be retained as the main, affiliation address. Superscript Arabic numerals are used for such footnotes.

\section{Submission checklist}

You can use this list to carry out a final check of your submission before you send it to the journal for review. Please check the relevant section in this Guide for Authors for more details.

Ensure that the following items are present:

- One author has been designated as the corresponding author with contact details:

- E-mail address

- Full postal address

All necessary files have been uploaded:

- Manuscript:

- Include keywords

- All figures (include relevant captions)

- All tables (including titles, description, footnotes)

- Ensure all figure and table citations in the text match the files provided

- Indicate clearly if color should be used for any figures in print

- Graphical Abstracts / Highlights files (where applicable)

- Supplemental files (where applicable)

- Further considerations

- Manuscript has been 'spell checked' and 'grammar checked';

- All references mentioned in the Reference List are cited in the text, and vice versa;

- Permission has been obtained for use of copyrighted material from other sources (including the Internet);

- Relevant declarations of interest have been made;

- Journal policies detailed in this guide have been reviewed;

- Referee suggestions and contact details provided, based on journal requirements. 